University of Nebraska - Lincoln

DigitalCommons@University of Nebraska - Lincoln

July 2008

\title{
Emotional and behavioral reactions to social undermining: $A$ closer look at perceived offender motives
}

Craig Crossley

University of Nebraska, Lincoln, ccrossley2@unl.edu

Follow this and additional works at: https://digitalcommons.unl.edu/managementfacpub

Part of the Management Sciences and Quantitative Methods Commons

Crossley, Craig, "Emotional and behavioral reactions to social undermining: A closer look at perceived offender motives" (2008). Management Department Faculty Publications. 1.

https://digitalcommons.unl.edu/managementfacpub/1

This Article is brought to you for free and open access by the Management Department at DigitalCommons@University of Nebraska - Lincoln. It has been accepted for inclusion in Management Department Faculty Publications by an authorized administrator of DigitalCommons@University of Nebraska - Lincoln. 
Published in Organizational Behavior and Human Decision Processes (2008); doi 10.1016/j.obhdp.2008.06.001

Copyright @ 2008 Elsevier Inc. Used by permission.

http://www.sciencedirect.com/science/journal/07495978

Submitted December 23, 2006; accepted June 2, 2008; published online July 11, 2008.

\title{
Emotional and behavioral reactions to social undermining: A closer look at perceived offender motives
}

\author{
Craig D. Crossley \\ Department of Management, University of Nebraska-Lincoln, \\ 1240114 CBA, Lincoln, NE 68588, USA \\ email ccrossley2@unl.edu
}

\begin{abstract}
This study examined how perceptions of underlying offender motives affect victims' emotional and behavioral reactions toward their offender. Perceived offender motives of malice and greed were embedded in a cognition-emotion-behavior model based on theories of attribution, forgiveness and revenge, and tested in the context of social undermining. Findings suggested that victims distinguished between offender malice and greed, and that these attributions shaped subsequent emotional reactions, which in turn demonstrated independent relations with revenge, avoidance, and reconciliation.
\end{abstract}

Keywords: motives, affect/emotion, social undermining, attribution, forgiveness, avoidance, anger, sympathy, revenge, generalizability, external validity

\section{Introduction}

Social undermining refers to intentional offenses aimed at destroying another's favorable reputation, their ability to accomplish their work, or their ability to build and maintain positive relationships (Duffy, Ganster, \& Pagon, 2002). It is critical to understand victims' reactions to social undermining in order to promote healthy workplace relationships, increase cooperation and trust, and prevent conflict escalation. The emerging research on social undermining suggests that victims' reactions depend largely on their own perceptions of an offense, and have damaging organizational outcomes such as increased counterproductive behaviors, reciprocated social undermining, and decreased job satisfaction and retention, as well as negative personal outcomes such as depression, decreased self-esteem, and psychosomatic symptoms (Duffy et al., 2006a; Duffy et al., 2006b; Duffy et al., 2002).

Although research has begun to underscore the impact of social undermining on individual and organizational well-being, several critical questions have yet to be examined and may provide important insights into how victims experience and react to being socially undermined. For instance, while research has found an important distinction between intentional versus accidental offense (Aquino et al., 2001; Martinko and Zellars, 1998; Weiner, 2006), research has yet to examine whether or to what extent offenders' underlying motives may affect victim reactions. Previous studies of social undermining have primarily focused on causes and consequences, assuming that the underlying motive is to harm the other, perhaps out of jealousy (Dunn \& Schweitzer, 2005). However, research has yet to examine other offender motives, such as self-promotion or greed.

Although research has yet to empirically examine the role of perceived offender motives, theorists as early as (Lewin, 1936) and (Heider, 1958) have suggested that identifying the function or purpose served by a particular behavior is essential in understanding why people act as they do. The importance of an offender's state of mind is further substantiated by the fact that actions that do not actually produce harm can engender negative reactions from would-be victims who believe that the offender had harmful motives (Miller, 2001). The criminal justice system has long recognized the importance of underlying offender motives. For instance, in the landmark DPP v. Smith case (1961), Smith was leaving a crime scene when a police officer jumped on top of his car. Smith's subsequent reckless driving caused the officer to fall from the car and get killed by oncoming traffic. In this case there was little doubt that Smith intentionally drove recklessly. However, the important question rising from this trial and shaping the legal definition of criminal intent hinged on Smith's underlying motives (i.e., escape vs. murder). 
Clearly, beyond what an offender may have done, victims' perceptions of why an offender acted as they did may provide essential cues in shaping victim reactions. To examine this question the present study embedded perceived offender motives within an integrated model of victim reactions based on attribution theory (Weiner, 1995), revenge theory (Bies and Tripp, 1996; Bies and Tripp, 1998) and a theoretical model of forgiveness (McCullough, Worthington, \& Rachal, 1997). This study empirically tested the effects of perceived motives on victim emotional and behavioral reactions by integrating experimental and fieldbased studies.

This study contributes to the literature in at least four ways. First, integrating key constructs from models of attribution (Weiner, 1995; Weiner, 2006), forgiveness (McCullough et al., 1997) and workplace revenge (Bies \& Tripp, 1996), this study represented a first attempt to empirically validate direct and indirect effects of perceived offender motives within a theoretical network of victim reactions.

Second, this study digs deeper into the intentional nature of workplace offenses to examine the role of underlying offender motives. In other words, moving beyond whether an offense was intentional, this study examines the relative and unique importance of specific motives of greed and malice in shaping victim responses to social undermining.

Third, using an integrated two-study approach, this research replicated findings across a lab experiment and a field study, with each approach compensating for limitations inherent in the other while maximizing both internal and external validity. The novel use of Multisample Structural Equation Modeling provides a useful template for triangulating findings across methodological approaches and answers the recent call of researchers concerned that measurement issues may invalidate comparisons of findings across different samples (Vandenberg and Lance, 2000; Williams et al., 2003). This approach is also of crucial importance in preventing research on attribution and workplace mistreatment from gravitating further into two distinct disciplines of study: one centering on questions answered only by experimental design, and the other around questions answered by a correlational approach (Rudolph, Roesch, Greitemeyer, \& Weiner, 2004).

Finally, the present study examined both pro-social as well as antisocial reactions to workplace mistreatment. This represents an important contribution in determining the broader effect of underlying motives on prohibiting positive responses as well as promoting negative ones, and provides a better understanding of the mechanisms involved in a range of victim responses to workplace offenses.

It is noteworthy that several difficulties arise in the study of offender motives. Two such difficulties are that offenders are often motivated to disguise their motives, and that victims may not accurately perceive their offenders' motive (Scott, 1985). While these inherent difficulties are not to be ignored in a systematic examination of offender motives, the focus of the present paper is whether victim's responses toward offenders are affected by their perceptions of the offender's motive. This is in line with research suggesting that people act according to their perceptions, which may or may not reflect objective conditions (e.g., Lazarus, 1999; Shapiro and Bies, 1994). Along these lines, Duffy and colleagues (2002, p. 332) suggested that "behavior is not considered undermining if it is not perceived as intentionally designed to hinder the target." Accordingly, this study examines victims' perceptions of undermining and does not address how these perceptions are formed, nor the accuracy of these perceptions.

Although numerous motives may exist for any given workplace offense, this study focuses on malice and greed as spe- cific underlying motives based on prior qualitative research on workplace revenge (Bies and Tripp, 1996; Bies and Tripp, 1998) and on criminal justice literature underscoring the importance of these specific motives (Povinelli, 2001). While findings are likely to generalize to other forms of workplace mistreatment, the present study was examined in the context of social undermining, as social undermining includes the notion of intentional behavior. This allows a test of the unique importance of perceived motives, over and above whether an offense was intentional versus accidental.

\section{Theoretical background and development of hypotheses}

Theories of attribution and reactions to offense often use the cognition-emotion-behavior sequence to explain victim responses. Using this sequence, the present study integrated elements from both top-down perspectives (i.e., attribution theory: Weiner, 1995; Weiner, 2006) that begin with a specific offense and examine a range of reactions, as well as bottom-up theories that focus on a specific reaction (i.e., forgiveness or revenge) and trace backward to a variety of antecedent emotions and cognitions. Key constructs were selected from these theoretical perspectives and integrated into the model used in this study. This model is depicted in Figure 1, and described in more detail below. This model serves as a theoretically derived nomological network that allows an examination of how perceived offender motives may prohibit pro-social emotions and behaviors and promote antisocial reactions.

Theoretical perspectives of how people respond to an offense, such as social undermining, often begin at the point where the offense is first recognized by the victim (Aquino et al., 2004; Bies and Tripp, 1996; Weiner, 1995). Once people determine that an offense was volitional, they begin an almost immediate sensemaking process to determine the offenders' underlying motives (Vonk, 1998).

The importance of underlying motives has been reflected in the American criminal justice system and termed mens rea (guilty mind) or "criminal intent." Along these lines, malice and greed represent two of the most commonly cited motives for criminal behavior (Povinelli, 2001), with resulting punitive damages in some cases of more than 500 times the cost of actual damages when "mean-spirited" or malicious motives were present (e.g., TXO Production Corp. v. Alliance Resources Corp., 1993). The legal definition of malice refers to a conscious, intentional wrongdoing, with the intention of doing harm to the victim out of illwill or hatred (Dictionary of Law, 2006). Malice further implies a deep-seated often unexplainable desire to see another suffer pain, injury, or distress (Merriam-Webster, 2006). On the other hand, greed connotes an instrumental and self-interested desire for wealth or gain, often at the expense of another or out of disregard for the others' well-being (Merriam-Webster, 2006).

This distinction parallels Bies and Tripp (1996) seminal research on workplace revenge where victims appeared to distinguish acts of malice from acts of greed. This study suggests that malicious offenders often single out a specific victim for personal reasons. Greedy offenders, on the other hand, opportunistically seek personal gain at the detriment of a convenient victim who happened to be in the wrong place at the wrong time.

While prior research suggests that underlying offender motives may be of great importance, research has yet to empirically examine the relative and unique associations between perceived offender malice and greed, and subsequent victim reactions. The present study extends research on social undermining and revenge by empirically examining perceived greed and malice as specific underlying motives for destroying another's reputation, relationships or ability to do their job. 


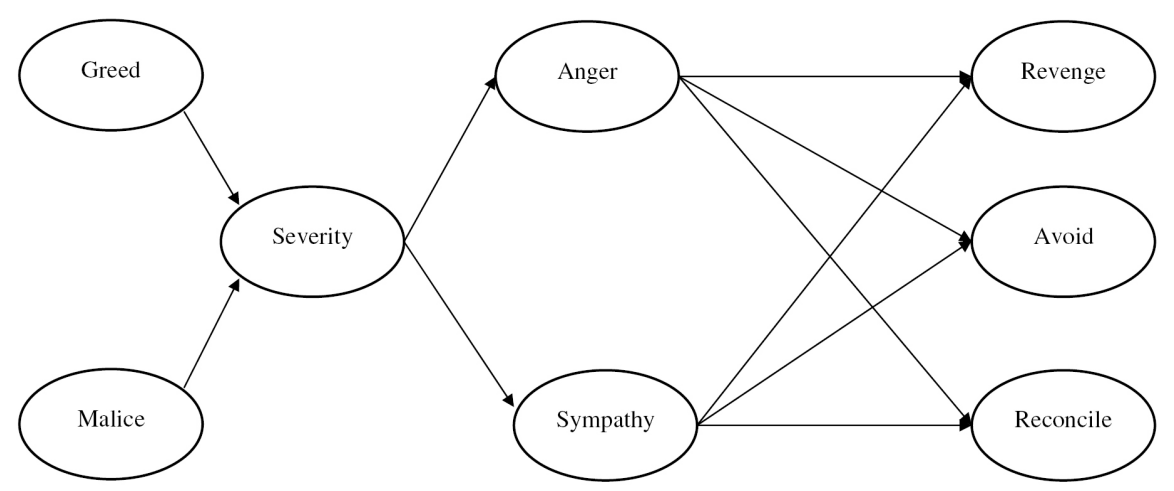

Figure 1. Integrated model of victim reactions to greed and malice motivated social undermining.

That victims give attention to their offender's motives suggests that motivated offenses may be perceived as more severe than offenses that lack an underlying, premeditated purpose (Miller, 2001). The mere fact that underlying malice or greed are present in an episode of social undermining may enhance victims' perceptions of offense severity as underlying motives signify the offender's guilty mind as evidenced by his or her subtle and calculated plans. Work on attribution theory provides insights into why underlying motives would generate stronger victim reactions. According to Weiner (1995), cause and blame attributions are evaluated along three primary dimensions. Locus of causality distinguishes causes generated internally (i.e., by the offender) or externally (i.e., by the situation), indicating who or what is to blame for the offense. Controllability refers to the degree of volitional control an offender had over the outcome, or the level of an offenders' accountability. Stability is the degree to which the cause is perceived to remain constant or to fluctuate, and indicates what to expect in the future under similar circumstances. Accordingly, when people sense premeditated underlying motives they may rule out situational causes and place more blame on the offender's shady and stable character (Reeder, $\mathrm{Ku}$ mar, Hesson-McInnis, \& Trafimow, 2002). The presence of underlying motives also signals high levels of offender control over the offensive behavior and subsequent outcome. Whereas an offender's character represents both stable and internal causes, victims may also expect continued mistreatment in the future. Offender motives may thus shape perceptions of offender character and convey important information to the victim, perhaps signaling that a malicious offender is out to get the victim, or that a greedy offender may undermine the victim whenever possible. Thus, underlying motives may make an offense appear more severe, perhaps due to an increased likelihood of reoccurrence and to questionable offender morals and values.

In their model of forgiveness in close relationships, McCullough and colleagues (McCullough et al., 1998; McCullough et al., 1997) posited that the perceived severity of an offense is a key factor that may play an essential role in translating offender behaviors into victim emotional and behavioral reactions. Whereas a severe offense is more likely to cause rumination and elicit anger and subsequent retaliation or avoidance, a minor offense is less likely to engender strong emotions and is easier to forgive.

Peoples' emotional reactions are inherently tied to attributional processes, with more severe offenses eliciting stronger emotions such as anger or rage (Aquino et al., 2004). Although the link between anger and revenge has been well documented (Aquino and Douglas, 2003; Berkowitz, 1990; Glomb, 2002), victims may not always act on their anger by seeking revenge. Rather, the tendency to overtly express aggression is often suppressed and replaced by more socially adapted reactions (Kup- pens, Van Mechelen, \& Meulders, 2004), such as avoidance (Georgakopoulos, 2004; O'Conner et al., 2001), or even reconciliation (McCullough et al., 1997; McCullough et al., 1998) and efforts to "tend-and-befriend" (Taylor et al., 2000).

In their model of forgiveness, McCullough et al. (1998, p. 1588) also suggested that positive, other-regarding emotions such as empathy serve an important gate-keeping role and "govern" prosocial reactions and forgiveness. These conceptual arguments suggest that a victim's ultimate actions toward an offender may be a function of other-condemning emotions such as anger, rage and hostility, or other-regarding emotions such as sympathy, empathy and compassion. In other words, anger and sympathy may represent independent emotional experiences that mediate the link between perceived offense severity and victim behavioral reactions. This notion is supported by research demonstrating modest to moderate negative correlations that are not so large as to suggest that these emotions merely reflect opposite ends of the same continuum (Rudolph et al., 2004; Weiner, 2006).

In the context of the present study, a victim of malice or greed driven social undermining may feel unsympathetic and less desirous to restore relations and more apt to avoid or seek revenge. Thus, unsympathetic victims may respond toward offenders with revenge or avoidance, but do so for slightly different reasons than when driven to act by anger. Indeed, anger often represents a hot emotional reaction (Bies \& Tripp, 1996) that may incite strong and immediate acts of revenge with the aim of harm or restitution, may promote avoidance out of repulsion and disdain, or may prevent reconciliation because of strong dislike or envy. Inversely, unsympathetic feelings may represent a more cold, cognitive reflection that is accompanied by depersonalization and a lack of regard for the offender. This hardened emotional state may not directly induce immediate reactions, but may rather "fail to forbid" rumination and calculated acts of vengeance and avoidance while dulling subsequent feelings of regret or immorality. Lacking sympathy, a victim may feel more justified in reacting negatively toward an offender. Unsympathetic victims may also be less apt to consider situational forces or an offenders' under-privileged upbringing that may have shaped the offenders' character, and consequently the victim may be less apt to try to reform, educate or help the offender. Lacking sympathy, victims may not overtly seek to harm their offender, but may feel apathetic and simply not be bothered or feel morally wrong if the offender is harmed by the victim's reactions to the original offense. In sum, distinct from anger, a lack of sympathy may not elicit sharp or immediate negative reactions, but may nevertheless fail to prevent desires and actions for revenge or avoidance, or may prohibit the desire for reconciling with an offender.

Based on the theoretical models reviewed above, anger is expected to be positively related to retaliation and avoidance (at- 
tribution theory, revenge theory), and negatively related to reconciliation (forgiveness model). Inversely, sympathy is expected to relate negatively to retaliation (attribution theory) and avoidance (forgiveness model), and positively to reconciliation (attribution theory, forgiveness model). While prior theoretical work substantiates the rationale for these relationships, the present study offers an important advancement over prior research on social undermining and workplace revenge, which has focused on anger as a single emotional reaction, by integrating conceptual ideas from McCullough and colleagues (1998 and 1997) and empirically examining both anger and sympathy as unique emotions that may independently affect behavioral reactions, mediating the effect of perceived offense severity.

A major implication from research on revenge (Bies and Tripp, 1996; Bies and Tripp, 1998) is that people's ability to distinguish offender malice from greed is important because it is instrumental in shaping their behavioral reactions toward offenders. For instance, victims may respond by avoiding a selfish offender who is looking for self-gain at the cost of a convenient victim. Findings also suggest that victims of a malicious offender may not be able to avoid, but may instead retaliate, perhaps to teach the offender a lesson or to prevent future offenses to themselves or others. The mediating role of perceived offense severity and emotions in translating perceived offender intentionality into victim's behavioral reactions is common among theoretical models of interpersonal conflict (Andersson and Pearson, 1999; Bies and Tripp, 1996; McCullough et al., 1997). Extending this prior conceptual and empirical research, attributions of offender malice and greed are also expected to relate to victim behavioral reactions indirectly through offense severity and subsequent anger and sympathy.

In summary, this review and integration of key elements from attribution, revenge and forgiveness theories establish the location and relationships of variables included in Figure 1, and center on the following mediational hypothesis which embeds offender motives within an integrated model of attribution, revenge, and reconciliation: perceived offender malice and greed will relate to victim revenge, avoidance, and reconciliation indirectly through perceived offense severity, and through subsequent emotions of anger and sympathy.

\section{Rationale and overview of the present study}

An integrated two-study approach was used to examine this model and triangulate research findings. Using a scenario-based technique, the first study experimentally manipulated offender motives and examined whether people reacted differently when the offender's motive was clearly made known to them. In an effort to extend findings beyond the hypothetical nature of the first study, Study 2 used a critical incident technique wherein people naturally attributed motives to their offender in the context of a real-life experience.

In line with the model forwarded in the present study, including multiple levels of mediators and multiple outcome behaviors, this study used Structural Equation Modeling to test direct and indirect effects. To present results from both studies in a more parsimonious fashion and offer a more direct statistical comparison of generalizability between study findings, a Multisample Structural Equation Modeling (MSEM) approach was used to simultaneously test the proposed model in both samples. Accordingly, the methods and results for both studies are presented together in a unified fashion.

The use of MSEM allowed a statistical comparison of regression coefficients across studies. This approach focuses on testing the similarity of relationships between motives and subsequent emotions and behaviors across studies. This approach does not equate "hypothetical" operationalizations of constructs in the lab to their "retrospective" operationalizations in the field. Rather, it examines whether the relationship between two constructs in the lab (e.g., "would feel angry" and "would seek revenge") is equivalent to the relationship between respective constructs in the field (e.g., relation between "felt angry" and "sought revenge"), and hence tests the generalizability of relationships (i.e., beta's) across studies, not whether operationalizations of constructs are identical. ${ }^{1}$ Notwithstanding the advance in MSEM in allowing a direct test of statistical relations, the valid interpretation of generalizability rests on the degree of similarity between operationalizations of constructs across methodological approaches. Accordingly, a great deal of effort was taken to use parallel items and measures, and to match measured with manipulated constructs as closely as possible across both studies.

The MSEM approach offers several advances over the more common practice of visually comparing findings across studies (e.g., Locke, 1986). Specifically, MSEM allows a statistical comparison of relationships across studies, and helps to rule out statistical artifacts such as measurement error and disparate factor structures or factor loadings as plausible alternative explanations when differences across studies are detected. This approach is also in line with recent arguments in the organizational sciences that suggest measurement invariance across samples is as critical of an issue as reliability when drawing correct inferences about study findings (Vandenberg and Lance, 2000; Williams et al., 2003).

\section{Method}

\section{Participants and procedures}

Lab study

One hundred and two undergraduate students (27\% male; age 19.1, SD .98) from a midsize Midwestern university were randomly assigned into a malicious $(n=33)$, greed $(n=37)$ or control condition $(n=32)$ and presented with a written scenario that described an incident wherein an offender purposefully gave them false information which caused them to fail on an important assignment. Similar to previous research on attribution (Rudolph et al., 2004) and reactions to offender motives (Reeder et al., 2002), scenarios explained identical offenses and outcomes, and differed only in regard to the specific motive underlying the offender's behavior. The scenario depicted an incident wherein a gender-neutral offender intentionally told the participant the wrong date for an important meeting. Because they acted according to this information, participants performed poorly on a key presentation and ultimately did not get the raise they had worked hard to obtain. Participants in the malice condition realized that the offender acted "out of pure dislike for you" and "strongly disliked you and was acting out of cruelty toward you personally." Participants in the greed condition came to realize that their offender acted "in a selfish effort to get a raise" and "was trying to get a promotion and would have done the same thing to anyone else who would have been in your position." In the control condition participants recognized that their offender "intentionally" gave them false information and "was

\footnotetext{
${ }^{1}$ Of particular importance, this approach does not equate offender motives presented to participants in the lab study with naturally perceived motives in the field study. Rather, this study acknowledges that subtle but important differences exist between objective offender motives presented to participants in the lab study and the subjective interpretation of offender motives in a real-life experience. This is in line with the focus of the present study on how people respond toward offenders once motives were attributed, not on differences in how attributions are formed or the accuracy of victim perceptions per se. Nevertheless, as presented below, results from the manipulation check suggest that in the lab study participants' perceptions largely reflected the objective motive presented in the scenario, and thus warrant the use of presented rather than perceived motives in the lab study and preserve the causal implications of findings.
} 
largely responsible for your misfortune" but were not given any insight into their offenders' motives. As a manipulation check, two items were included that asked participants to rate the extent to which the offense was motivated by greed ("To what extent was [the offender] acting out of selfishness") and malice ("To what extent was [the offender's] action motivated simply by meanness or cruelty"). Participant responses were subjected to a one-way ANOVA with planned comparisons. As expected, participants in the malicious condition viewed the offenders' behavior as more cruel $t=4.28, p<.001$ than participants in the greed and control conditions. Participants in the greed condition viewed their offenders behaviors as more selfish $t=3.20, p<.01$ than participants in the malicious and control conditions. These findings suggest that the motives presented to participants were perceived as expected.

\section{Field study}

A self-administered survey was distributed to faculty of a midsize Midwestern university via campus mail. The survey used a critical incident technique used in previous studies of revenge and forgiveness (e.g., Aquino et al., 2001; McCullough et al., 1998). Participants were asked to recall an instance when someone at work intentionally tried to ruin their reputation or undermine their ability to do their job. To help participants more vividly recall the incident, they were asked to briefly describe what the offender did, what the offender was trying to accomplish, and how they responded toward the offender. After describing the incident, participants were asked several followup questions described below. To help mitigate socially desirable responding, surveys were completely anonymous and were returned in unmarked envelopes via campus mail. One hundred and twelve participants were able to recall an incident of social undermining and returned useable surveys ( $\mathrm{M}$ age $=47.5$, $\mathrm{SD}=10 ; 51 \%$ male, $47 \%$ tenured). Respondents did not differ in terms of gender $\chi^{2}(1)=2.95, p>.05$, tenure status $\chi^{2}(1)=0.39$, $p>.05$, or age $t(239)=-1.40, p>.05$. Examples of social undermining included "a colleague voted against my tenure because they were at odds with my mentor, and were trying to get back at him" and "an IT [information technology] person that I was having problems with installed a remote tracking program on my computer in an effort to get me fired because of personal motives."

\section{Measures}

\section{Motives}

In the lab study experimental conditions were dummy-coded to create two single-item variables, with the control condition serving as the dummy variable. In the field study, offender greed was assessed with the following three questions developed for this study and based on Bies and Tripp (1996): to what extent "did the person act out of selfishness," "was the person thinking of him or her self," and "was the person looking out for him or her self" $(a=.85)$. Offender malice was also measured with a three-item scale that asked participants: to what extent "did the person have it out for you personally," "did the person dislike you," and "was the person trying to attack you personally" $(a=.90)$. Responses were indicated on a 5-point scale ranging from (1) to a very little extent, to (5) to a very large extent.

\section{Perceived offense severity}

Offense severity was measured with a 3-item scale based on Aquino, Tripp, and Bies (2006). Participants in both studies were asked to indicate how "severe" how "hurtful" and how "wrong" the offense was on a 10 point scale anchored with (1) not at all and (10) extremely; $a=.80$ lab; .82 field.

\section{Emotional reactions}

Anger was assessed by asking participants the extent to which they would feel (lab) or had felt (field) "angry," "hostile," and "enraged" toward their offender on a scale ranging from (1) not at all to (5) a lot ( $a=.72, .85$, respectively). Sympathy toward the offender was assessed in the same way with the adjectives "compassionate," "empathetic," and "sympathetic" ( $a=.70, .76$, respectively).

\section{Behavioral reactions}

Revenge was assessed in the lab study with the following three items from Aquino et al. (2001) rewritten to reflect the hypothetical scenario used in the present study: "I would do something to make [the offender] get what [the offender] deserves," "I would make something bad happen to [the offender]," and "I would do something to make [the offender] pay" ( $a=.88)$. Revenge was assessed in the field study with the following three items from Aquino et al. (2001) "I did something to make them get what they deserve," "I tried to make sure something bad would happen to them," and "I did something to make them pay" $(a=.88)$. Avoidance was assessed in the lab with the following three items rewritten from McCullough et al. (1998) "I would avoid [the offender]," "I would live as if [the offender] didn't exist, wasn't around," and "I would cut off my relationship with [the offender]" $(a=.92)$. Avoidance was assessed in the field study with the same items written to reflect a past incident $(a=.88)$. Reconciliation was assessed with the following three items rewritten from Aquino et al. (2001): "I would try to make amends," "I would give [the offender] a new start," and "I would make an effort to be more friendly and concerned" $(a=.93)$. Reconciliation was assessed in the field study with the same items written to reflect a past incident $(a=.92)$. Responses on all scales ranged from (1) strongly disagree to (7) strongly agree.

\section{Results}

Results are presented in the following order. First, a measurement model was tested to ensure that items loaded on respective factors as expected. Second, in an effort to mitigate concerns of common method variance, several common method models were compared to the measurement model. Next, a series of plausible alternative models of direct and indirect effects were examined. In the fourth phase of analyses, relationships between variables in the lab study were compared to synonymous relationships in the field study. This provided a statistical test of whether specific relationships generalized between samples, methodologies, and across type of offense. Finally, based on results from various model comparisons, the study hypothesis and direct and indirect effects of study variables were examined in the ultimately best fitting model.

\section{Descriptive statistics}

Means, standard deviations, and intercorrelations between observed study variables are displayed in Table 1, with lab sample correlations below the main diagonal and field sample correlations above the main diagonal.

\section{Measurement model}

Multisample Confirmatory Factor Analysis (MCFA) was used to test invariance of the factor structure across groups to ensure that respective items were invariant between studies (Vandenberg \& Lance, 2000). For instance, the item "I would avoid my offender" should relate to the latent variable "would avoid" in the lab study to the same degree and magnitude that the item "I 
Table 1. Correlations between study variables for Study 1 and Study 2

\begin{tabular}{|c|c|c|c|c|c|c|c|c|c|c|c|c|}
\hline Variable & 1 & 2 & 3 & 4 & 5 & 6 & 7 & 8 & $\begin{array}{l}\text { Lab } \\
\text { Mean }\end{array}$ & SD & $\begin{array}{l}\text { Field } \\
\text { Mean }\end{array}$ & SD \\
\hline 1. Malice & & .12 & $.22^{*}$ & .08 & .01 & .03 & .16 & $-.27^{\star *}$ & -- & -- & 3.91 & 1.15 \\
\hline 2. Greed & $-.50^{* *}$ & & $.24^{*}$ & $.26^{* *}$ & -.06 & .15 & .18 & $-.22^{*}$ & -- & -- & 2.93 & 1.38 \\
\hline 4. Anger & $.23^{*}$ & .00 & $.45^{* *}$ & & $-.28^{* *}$ & $.29^{* *}$ & $.45^{* *}$ & $-.26^{* *}$ & 4.33 & 0.64 & 3.39 & 1.12 \\
\hline 5. Sympathy & -.01 & -.02 & -.06 & -.12 & & .02 & $-.28^{* *}$ & $.27^{* *}$ & 1.63 & 0.70 & 1.48 & 0.65 \\
\hline 6. Revenge & -.07 & .09 & .09 & $.28^{* *}$ & -.01 & & .06 & -.13 & 3.49 & 1.50 & 1.60 & 1.08 \\
\hline
\end{tabular}

Note. ${ }^{* *} p<.01,{ }^{*} p<.05$. Values on the bottom half of the table represent correlations among variables in the lab study; $N=106$. Correlations in the top half of the table represent correlations among variables in the field study; $N=112$. Descriptive statistics are based on observed scale composite scores.

avoided my offender" relates to the latent variable "did avoid" in the field study. The measurement model was specified in the following manner. First, the latent variable for malice [greed] was specified by setting the factor loading of the dummy-coded malice [greed] variable to unity (i.e., 1.00). The dummy variable representing the control condition is thus a redundant variable and is statistically controlled in the present model. ${ }^{2}$ Because MCFA requires the same number of indicators in both samples, scale scores for malice and greed were used as single indicators in the field study.

Factor loadings for respective items were fixed in the field sample to be equal to respective item loadings in the lab sample. This approach allowed subsequent comparisons between lab and field studies to rule out important statistical artifacts (i.e., unreliability and factor structure/loadings) as possible alternative explanations when differences in regression coefficients were detected across studies. The MCFA was tested via Lisrel 8.35 and demonstrated adequate fit to the data $\chi^{2}(353)=541.34$, $p<.05 ; x^{2} / d f=1.53$, RMSEA $=.075, \mathrm{CFI}=.85$. Findings suggested that corresponding scale items shared statistically equivalent factor loadings to respective latent variables across lab and field samples. All estimated indicators significantly loaded on respective latent variables $\lambda=.66$ to .94 ; median $=.84$.

\section{Common factor model}

Alternative models were next compared to help rule out common method variance (e.g., self-report bias, demand characteristics, retrospective bias) as an explanation for study findings, and to demonstrate evidence of discrimination between study variables. The first model specified a common factor underlying motives, perceived severity, and emotion items, whereas revenge, avoidance, and reconciliation behaviors were specified on three separate factors. This model was inferior to the measurement model $\chi^{2}(374)=1127.44, p<.01 ; \chi^{2} / d f=3.01$, RMSEA $=.14$, $\mathrm{CFI}=.62$. Next, a five-factor model was generated wherein perceived motives and perceived severity items loaded a common method factor, emotion items loaded a second common method

\footnotetext{
${ }^{2}$ Similar constraints also existed in the field condition, as the intentional nature of the offense was methodologically controlled by asking participants to describe an event in which their offender intentionally undermined them. As a manipulation check, participants responded to a three-item scale (e.g., "to what extent where the person's behaviors intentional" $a=.91$ ) that ranged from 1 ) "a very little extent" to 5) "a very large extent." All participants indicated scores greater than 3 ("a moderate extent"), and the average score was $4.6(S D=.56)$, with a modal response of $5(69 \%)$. Thus, parallel to the control condition in the lab study, offenders' behaviors could be intentional, but without discernable motives of malice or greed. Whereas malice and greed are treated as uncorrelated orthogonal constructs in the experimental study, the field sample allowed malice and greed to assume their natural relationship by freeing the respective parameter.
}

factor, and revenge, avoidance, and reconciliation each loaded on three separate factors. This model was also inferior to the measurement model $\chi^{2}(370)=931.64, p<.01 ; \chi^{2} / d f=2.52$, RM$\mathrm{SEA}=.12, \mathrm{CFI}=.68$ and supported the distinction between anger and sympathy. Although these alternative model comparisons do not rule out the possibility of some common method variance, results do suggest that study findings are not best explained as an artifact of common method variance.

\section{Model comparisons}

Following the approach suggested by Anderson and Gerbing (1988), the fully mediated model $\left(M_{\mathrm{H}}\right)$ was tested against alternative models that included direct links in addition to hypothesized indirect paths. These model comparisons are summarized in Table 2. Although results largely supported the hypothesized model, findings also suggested the inclusion of two direct paths. Accordingly, a revised partially-mediated model was specified that, in addition to relations denoted in Figure 1, included a path from greed to reconciliation and a path from malice to anger $M_{\mathrm{H} 2} \chi^{2}(345)=500.18, p<.05 ; \chi^{2} / d f=1.45$, RMSEA $=.065$, $\mathrm{CFI}=.88$

\section{Tests of generalizability}

Next, a statistical test of the generalizability of relations between respective variables in lab and field studies was conducted. This was done by creating separate models wherein each regression path in the field sample was freed in isolation and the $x^{2}$ for the model with the freed path was compared to the chi-square for the model with the path constrained to be equal across studies. A significant $\chi^{2}$ difference test indicates that the lab and field path coefficient is statistically different. As seen in Table 3, the $\chi^{2}$ difference tests found that the majority of path weights were invariant across studies, suggesting that relationships between variables in the field study largely replicated findings in the lab study in both direction and magnitude. This important finding indicates that relations between the presented offender motives and what people suggested they would do in a hypothetical situation largely matched relations between perceived offender motives and what other people said they had done when socially undermined.

Not all path coefficients were invariant between lab and field. Results from the $\chi^{2}$ difference tests indicated that paths between (1) greed and offense severity, (2) anger and revenge, and (3) anger and reconciliation lacked invariance between lab and field samples. These findings are consistent with work by Locke (1986) suggesting that effects are often stronger in lab studies that isolate study variables from extraneous variables. The difference in greed and offense severity relations may be related to the fact that offenders' motives were specified in the lab scenario, whereas in a non-contrived experience and across various 
Table 2.. Results for structural model nested comparisons

\begin{tabular}{|c|c|c|c|c|c|c|c|}
\hline \multirow{2}{*}{$\frac{\text { Model }}{\text { Hypothesized model }\left(M_{\mathrm{H}}\right)}$} & \multirow{2}{*}{$\frac{x^{2}}{517.75^{* *}}$} & \multirow{2}{*}{$\frac{\text { df }}{347}$} & \multirow{2}{*}{$\frac{x^{2} / \mathrm{df}}{1.49}$} & \multirow{2}{*}{$\frac{\text { RMSEA }}{0.068}$} & \multirow{2}{*}{$\frac{\text { CFI }}{0.87}$} & \multicolumn{2}{|c|}{$\begin{array}{l}\chi^{2}(\mathrm{df}) \text { difference } \\
\text { vs. hypothesized } \\
\text { model }\end{array}$} \\
\hline & & & & & & & \\
\hline $\begin{array}{l}M_{\mathrm{H}} \text { plus six direct paths from malice and from } \\
\quad \text { greed to revenge, avoidance, and reconciliation } \\
M_{\mathrm{H}} \text { plus Malice } \rightarrow \text { Revenge effect } \\
M_{\mathrm{H}} \text { plus Malice } \rightarrow \text { Avoidance effect } \\
M_{\mathrm{H}} \text { plus Malice } \rightarrow \text { Reconciliation effect } \\
M_{\mathrm{H}} \text { plus Greed } \rightarrow \text { Revenge effect } \\
M_{\mathrm{H}} \text { plus Greed } \rightarrow \text { Revenge effect } \\
M_{\mathrm{H}} \text { plus Greed } \rightarrow \text { Avoidance effect } \\
\left.M_{\mathrm{H}} \text { plus Greed } \rightarrow \text { Reconciliation effect (Modified } M_{\mathrm{H}} 1\right)\end{array}$ & $\begin{array}{l}504.70^{* *} \\
517.11^{* *} \\
517.70^{* *} \\
517.04^{* *} \\
516.04^{* *} \\
516.04^{* *} \\
515.74^{* *} \\
505.94^{* *}\end{array}$ & $\begin{array}{l}341 \\
346 \\
346 \\
346 \\
346 \\
346 \\
346 \\
346\end{array}$ & $\begin{array}{l}1.48 \\
1.49 \\
1.5 \\
1.49 \\
1.49 \\
1.49 \\
1.49 \\
1.46\end{array}$ & $\begin{array}{l}0.067 \\
0.068 \\
0.068 \\
0.068 \\
0.068 \\
0.068 \\
0.067 \\
0.065\end{array}$ & $\begin{array}{l}0.88 \\
0.87 \\
0.87 \\
0.87 \\
0.87 \\
0.87 \\
0.88 \\
0.88\end{array}$ & $\begin{array}{l}13.05^{*} \\
0.64 \\
0.05 \\
0.71 \\
1.73 \\
1.73 \\
2.01 \\
11.81^{\text {** }}\end{array}$ & $\begin{array}{l}(6) \\
(1) \\
(1) \\
(1) \\
(1) \\
(1) \\
(1) \\
(1)\end{array}$ \\
\hline $\begin{array}{l}\text { Modified } M_{\mathrm{H}} 1 \text { plus seven direct paths from malice to anger } \\
\quad \text { from severity to revenge, avoidance, and reconciliation } \\
M_{\mathrm{H}} \text { plus Malice } \rightarrow \text { Anger effect } \\
M_{\mathrm{H}} \text { plus Malice } \rightarrow \text { Sympathy effect } \\
M_{\mathrm{H}} \text { plus Greed } \rightarrow \text { Anger effect } \\
M_{\mathrm{H}} \text { plus Greed } \rightarrow \text { Sympathy effect } \\
M_{\mathrm{H}} \text { plus Severity } \rightarrow \text { Revenge effect } \\
M_{\mathrm{H}} \text { plus Severity } \rightarrow \text { Avoidance effect } \\
M_{\mathrm{H}} \text { plus Severity } \rightarrow \text { Reconciliation effect }\end{array}$ & $\begin{array}{l}\text { d sympat } \\
508.70^{* *} \\
512.54^{* *} \\
517.67^{* *} \\
516.06^{* *} \\
516.98^{* *} \\
516.19^{* *} \\
516.98^{* *} \\
516.22^{* *}\end{array}$ & $\begin{array}{l}\text { from } \\
340 \\
346 \\
346 \\
346 \\
346 \\
346 \\
346 \\
346\end{array}$ & $\begin{array}{l}1.5 \\
1.48 \\
1.5 \\
1.49 \\
1.49 \\
1.49 \\
1.49 \\
1.49\end{array}$ & $\begin{array}{l}\text { and sy } \\
0.068 \\
0.068 \\
0.068 \\
0.068 \\
0.068 \\
0.067 \\
0.068 \\
0.067\end{array}$ & $\begin{array}{l}\text { hy, an } \\
0.87 \\
0.88 \\
0.87 \\
0.87 \\
0.87 \\
0.87 \\
0.87 \\
0.87\end{array}$ & $\begin{array}{l}9.05 \\
5.21^{*} \\
0.08 \\
1.69 \\
0.77 \\
1.56 \\
0.77 \\
1.53\end{array}$ & $\begin{array}{l}(7) \\
(1) \\
(1) \\
(1) \\
(1) \\
(1) \\
(1) \\
(1)\end{array}$ \\
\hline $\begin{array}{l}\text { Modified Hypothesized Model } 2\left(M_{\mathrm{H}} M_{\mathrm{H}} 2\right) \text {. Hypothesized } \\
\text { greed to reconciliation and malice to anger }\end{array}$ & $\begin{array}{l}\text { ly mediate } \\
500.18^{* *}\end{array}$ & $\begin{array}{c}\text { mode } \\
345\end{array}$ & s direc & $\begin{array}{l}\text { aths from } \\
0.65\end{array}$ & .88 & & \\
\hline
\end{tabular}

Note. ${ }^{* *} p<.01,{ }^{*} p<.05$. Combined $N=218$. CFI is the comparative fit index; RMSEA is the root-mean-square error of approximation.

Table 3. Results for structural model nested comparisons and invariance between path weights

\begin{tabular}{lcccccc}
\hline & $x^{2}$ & $d f$ & $x^{2} / d f$ & RMSEA & CFI & $\begin{array}{l}\chi^{2}(d f) \text { difference vs. } \\
\text { hypothesized model }\end{array}$ \\
\hline Modified Hypothesized Model $2\left(M_{\mathrm{H} 2}\right)$ & $500.18^{* *}$ & 345 & 1.45 & .065 & .88 & \\
Compared (freed) Path & & & & & & $0.16(1)$ \\
Malice $\rightarrow$ Severity & $500.02^{* *}$ & 344 & 1.45 & .065 & .88 & $.196^{*}(1)$ \\
Greed $\rightarrow$ Severity & $495.22^{* *}$ & 344 & 1.44 & .064 & .88 & $0.71(1)$ \\
Severity $\rightarrow$ Anger & $499.47^{* *}$ & 344 & 1.45 & .065 & .88 & $0.00(1)$ \\
Severity $\rightarrow$ Sympathy & $500.18^{* *}$ & 344 & 1.45 & .065 & .88 & $4.52^{*}(1)$ \\
Anger $\rightarrow$ Revenge & $495.66^{* *}$ & 344 & 1.44 & .064 & .88 & $1.43(1)$ \\
Anger $\rightarrow$ Avoid & $498.75^{* *}$ & 344 & 1.45 & .065 & .88 & $11.10^{* *}(1)$ \\
Anger $\rightarrow$ Reconciliation & $489.08^{* *}$ & 344 & 1.42 & .062 & .88 & $.53(1)$ \\
Sympathy $\rightarrow$ Revenge & $498.65^{* *}$ & 344 & 1.45 & .065 & .88 & $0.44(1)$ \\
Sympathy $\rightarrow$ Avoid & $499.74^{* *}$ & 344 & 1.45 & .065 & .88 & $.0 .13(1)$ \\
Sympathy $\rightarrow$ Reconciliation & $500.05^{* *}$ & 344 & 1.45 & .065 & .88 & $0.13(1)$
\end{tabular}

Note. ${ }^{* *} p<.01,{ }^{*} p<.05$. Combined $N=218$. The modified hypothesized model with all paths set invariant (top) was compared (via $\chi^{2}$ difference test) to each of the reduced models (with one path freed at a time) one at a time, in sequence.

types of offense, people may be less certain of offender motive thus attenuating the relation between greed and severity. Further, in a benign laboratory condition void of other contextual factors that may moderate this relation, offender selfishness may be more salient and share a stronger direct relation with offense severity. The difference between anger and revenge relations suggests that outside of the lab revenge may be a less viable response toward offenders. This may also be related to differences in social desirable responding across studies. The difference between anger and reconciliation relations suggests that anger is more strongly related to withholding reconciliation in the lab context. Outside of the lab, a number of contextual factors, such as work interdependence, hierarchical status, or mutual friends may moderate the relation between anger and reconciliation leading to weaker direct relations.

Based on findings that not all paths were statistically invariant across both samples, a final model was generated wherein the three paths that differed between lab and field study were freed in unison in the field sample. Results of the specific path coefficients from this final model are reported in Figure 2. This model demonstrated adequate fit to the data $\chi^{2}(342)=497.96$, $p<.05 ; x^{2} / \mathrm{df}=1.46$, RMSEA $=.061, \mathrm{CFI}=.89$, and a significant improvement over the baseline hypothesized model $M_{\mathrm{H}}$ $\Delta \chi^{2}(5)=19.79, p<.01$ and was used to examine direct and indirect effects of malice and greed on victim reactions toward their offender.

\section{Direct and indirect effects}

Direct relationships between study variables are presented in Figure 2. As expected, perceived malice predicted unique variance in offense severity in lab and field samples $(\beta=.20, p<.01)$, over and above greed and no-motive conditions. Perceived offender greed was also related to offense severity over and above malice and no-motive conditions in field $(\beta=.23, p<.05)$ and lab samples $(\beta=.84, p<.001)$. As expected, offense severity was positively associated with anger $(\beta=.53, p<.001)$; however, severity was not significantly associated with sympathy toward the offender $(\beta=-.12, p=.07$ 1-tail) in either the lab or the field samples. In addition to model tests comparing direct and indirect paths between perceived offender motives and victim emotional reactions (See Table 2), significance tests of indirect effects 


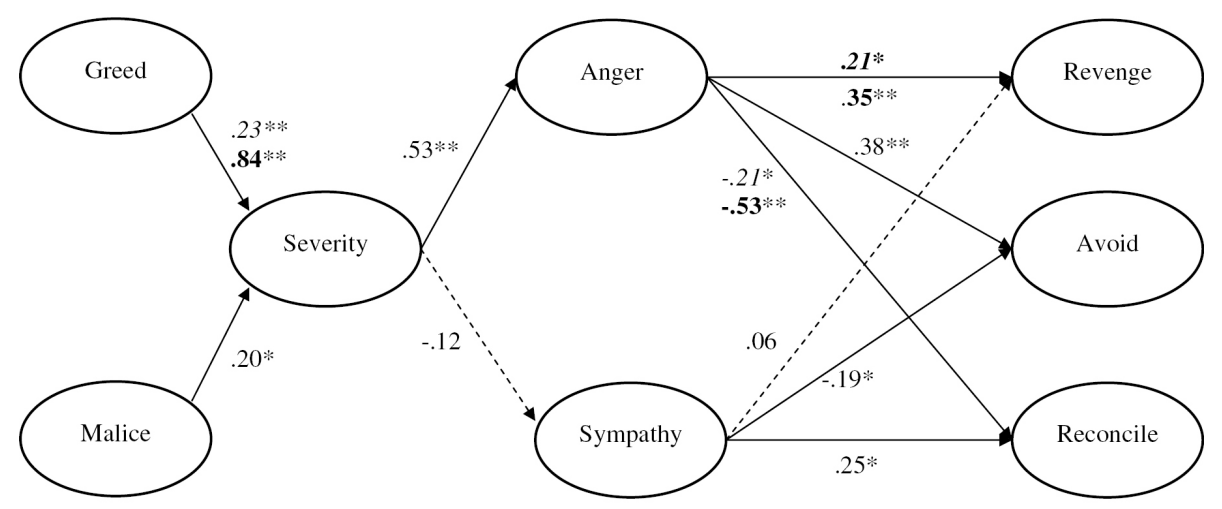

Figure 2. Integrated model and results of final structural model. Note. $\chi^{2}(342)=497.96, p<.05 ; \chi^{2} / \mathrm{df}=1.46, \mathrm{RMSEA}=.061, \mathrm{CFI}=.89 .{ }^{* *} \mathrm{p}<.01$, ${ }^{*} \mathrm{p}<.05$. Path weights are reported as standardized coefficients. When path coefficients differed between samples, bold numbers represent coefficients from the lab sample, and values in italics represent coefficients from the field study. Solid lines represent significant paths, whereas dashed lines represent non-significant paths. Direct paths from Malice to Anger (.16* lab and field) and from greed to reconciliation ( $-.22^{* *} l a b$ and field), and the correlation between malice and greed $\left(-.89^{* *}\right.$ lab, .09 field) are not shown in the model above.

provided additional support for the indirect effect of malice on anger $(b=.07, p<.01)$, but not on sympathy $(b=-.02, n s)$. The indirect effects of greed on anger (lab $b=.32, p<.01$; field $b=.10$, $p<.05)$ were as expected, whereas indirect effects on sympathy were not significant (lab $b=-.09$, ns; field $b=-.03, n s$ ).

Consistent with expectations, anger related positively to revenge and avoidance, and negatively to reconciliation in the field $(\beta=.21 ; \beta=.38 ; \beta=-.21$, respectively; all $p<.01)$, and in the lab $(\beta=.35 ; \beta=.38 ; \beta=-.53$, respectively; all $p<.01)$. Sympathy was related negatively to avoidance in both samples $(\beta=-.19$, $p<.05)$ and positively to reconciliation in both samples $(\beta=.25$, $p<.05$ ), but was not significantly related to revenge in either sample $(\beta=.06, n s)$.

The major hypothesis of this study suggested that the relation between perceived offender motives and victim behavioral reactions would be mediated by perceived severity, and subsequent anger and sympathy. Whereas comparative model tests offered initial support for mediation (Table 2), significance tests of indirect effects provided further evidence of mediation. Specifically, malice related indirectly to revenge $(b=.19, p<.05)$, avoidance $(b=.09, p<.01)$, and reconciliation $(b=-.15, p<.001)$ in the lab sample, and to avoidance in the field sample $(b=.09, p<.01)$. Greed also related indirectly to revenge $(b=.31, p<.01)$, avoidance $(b=.15, p<.01)$ and reconciliation $(b=-.27, p<.01)$ in the lab sample, and to avoidance $(b=.05, p<.05)$, but not revenge $(b=.03, n s)$ or reconciliation $(b=-.03, n s)$ in the field study. That indirect effects were not fully replicated in the field was not overly surprising given the stronger direct effects in the lab, consistent with Locke (1986). Nevertheless, the significant direct relations between variables in the model linking perceived motives to victim reactions leads to the same practical conclusions regarding interventions aimed at breaking causal links between variables and preventing conflict escalation.

\section{Discussion}

Several key findings emerged from this study. First, perceptions of offender malice were directly associated with the perceived severity of an offense. Second, perceptions of malice related to revenge, avoidance, and reconciliation behaviors indirectly through perceived offense severity and subsequent feelings of anger. Third, perceptions of offender greed were also related to perceived offense severity. Fourth, perceived offender greed was related to revenge, avoidance, and reconciliation indirectly through perceived severity and subsequent anger. Fifth, perceived malice and perceived greed each accounted for unique variance in perceived severity, anger, and behavioral outcomes, unexplained by the other motive. Sixth, anger and sympathy each predicted unique variance in avoidance and reconciliation. Together these findings provide insights into how and how much perceived offender motives and subsequent victim emotions affect victim behavioral reactions toward one's offender.

Overall, results provided empirical support for the assertion that victims' perceptions of offenders' underlying motives are important predictors of victim reactions and that malice and greed motives can be distinguished in meaningful ways. The similar pattern of findings across studies suggest that whether victims naturally inferred or were provided insights into their offender's motives, victims' emotional and behavioral reactions unfolded in the same fashion with generally stronger results in the lab study.

While the aim of this study was to embed perceived offender motives within a network of integrated core constructs from several theories rather than to provide a test of these theories per se, findings provide important insights into the theories on which the model was based. Findings from the present study have several important implications for revenge theory (Bies and Tripp, 1996; Bies and Tripp, 1998). First, this study provides empirical support for the previously untested core proposition that offender malice and greed may uniquely shape people's reactions to an attack on their social identity, and are therefore important elements of an offense. Second, findings demonstrate how perceived motives affect victim reactions through increased perceived severity of an offense and subsequent feelings of anger. Finally, this study suggested that effects of underlying motives extend beyond revenge to predict avoidance and reconciliation.

These results extend work on attribution theory by suggesting that beyond attributions of intentional vs. accidental behavior, perceptions of specific underlying motives are of particular importance in shaping victims' reactions toward offenders. These findings extend earlier work by Bradfield and Aquino (1999) and suggest that offender underlying motives may be an explanatory mechanism whereby blame attributions relate to workplace forgiveness and revenge. Findings also inform models of interpersonal forgiveness (McCullough et al., 1997; McCullough et al., 1998) and suggest that independent from other-regarding emotions like sympathy, diffusing other-condemning emotions such as anger may help promote forgiveness. Findings also suggested that theories of revenge (Bies \& Tripp, 1996), forgiveness (McCullough et al., 1997), and attribution (Weiner, 1995) may be meaningfully integrated to provide a more holistic framework of pro-social and antisocial responses to workplace events. 
Overall, findings regarding emotions are in line with the recent focus on affect in the workplace and in the attribution process. For instance, Weiner (2006) suggested that anger and sympathy represent the two key "moral emotions" that provide necessary bridges between attributions and reactions. Weiner (p. 35) further argued that anger represents a value judgment following from the belief that another "could and should have done otherwise." In a similar vein, fairness theory (Folger \& Cropanzano, 1998) suggests that attributions of organizational justice are also based on moral and ethical evaluations of what could have, should have and would have transpired under fair conditions, and that this discrepancy can engender anger and retaliation. In a contrasting view, sympathy is also considered a moral emotion (Weiner, 2006), however this emotion has generally been discussed as an equal and opposite emotion from anger, existing when others are excused from responsibility or blame. Nevertheless, sympathy might also play an interfering role in the justice process by coloring our view of an offender and insulating him or her from the natural social consequences that befall offensive behavior (Moore, 1998). Taken together, these conceptual arguments suggest that both anger and sympathy may be critical emotional antecedents of revenge, avoidance, and reconciliation.

Contrary to expectations, offense severity was not found to relate to sympathy. Further, findings may suggest that feeling unsympathetic toward one's offender may not incite revenge responses, at least not beyond the effect of anger. Sympathy was associated with avoidance and reconciliation suggesting that it is an important emotion in determining these reactions. Together this pattern of results underscores the need for future research to identify factors not included in the current model that may affect sympathy, such as quality of relationship with one's offender, perceived similarity, or offender likability (Bradfield and Aquino, 1999; Kim et al., 2008). Future research may also examine moderators of the relation between sympathy and revenge. For instance, one's desire for social justice may lead a victim to retaliate regardless of sympathetic feelings toward an offender in order to teach the offender a hard lesson or to protect future would-be victims (Bies \& Tripp, 1998). Alternatively, it is plausible that an unsympathetic victim may chose not to seek revenge based on her strong moral self-identity (Aquino \& Reed, 2002).

Although this study mainly focuses on a theoretical model, there are also several important managerial implications. For example, the workplace can be a political battlefield for those clamoring for promotion and advancement or those competing for limited resources. As such, social undermining and other forms of mistreatment may abound in some work settings. Because perceptions of malicious intent may incite revenge, one way that managers may reduce conflict escalation is by using inductive personality tests such as the Conditional Reasoning Test for Aggression to screen out job applicants who are predisposed to perceive an offense or malicious intent, or to justify (re)acting in interpersonally aggressive ways (Bing et al., 2007; James et al., 2005). These tests may also provide useful information when making promotion decisions, as people moving into leadership positions may create climates that implicitly endorse aggression and social undermining. In some instances strong policies and punishments for those who perpetuate social undermining may further prohibit retaliation (Trevino, 1992; Trevino and Ball, 1992), although such policies may be limited in their ability to promote reconciliation or to prevent avoidance. Formal grievance mechanisms and trained conflict mediators may also help prevent revenge and avoidance while promoting reconciliation in the workplace. Qualitative research on revenge suggests that victims often talk to coworkers to validate their perceptions of an offender's motive (Bies \& Tripp, 1996). Accordingly, manag- ers may do well to proactively develop climates of trust, social support, and transparency rather than allow climates that support rumor-mills and suspicion, where inferences of ulterior motives may flourish. Whereas competition for limited resources may engender greed driven offenses, clear policies and pathways to obtaining resources may help to reduce selfish acts of social undermining. Compensation systems that promote competition and individual performance may also be closely examined for unintentionally rewarding social undermining. For instance, some commission based jobs may promote undermining a colleague's reputation or competence in order to win over his or her valued customers.

One important methodological contribution of this study is the use of MSEM to statistically test the generalizability of findings between studies. This approach compliments the "practical significance" approach taken by Rudolph et al. (2004), and offers a template for future studies attempting to compare findings across methods and studies. The use of MSEM in this study eliminates measurement artifacts as alternative explanations when differences were detected between studies. This also integrates recent arguments for testing invariance when comparing findings across samples (Vandenberg \& Lance, 2000).

One strength of this study was that the model was examined using both experimental and correlational data. The extent to which causal relations in the lab study were similar to findings in the field study supports the causal ordering of variables, bolstering internal validity and substantially strengthening inferences of causality implicitly made when using SEM and testing for mediation. Further, the extent to which findings generalized from one sample to the other was directly tested providing evidence of external validity. Along these lines, seven of ten relationships between model variables were statistically invariant in both direction and magnitude across studies. The three relationships that did vary across samples differed in magnitude, but not direction (i.e., were significantly different than zero in the same direction). Taken together, these findings suggest that attributional processes may be studied via scenario-based methods with a fair degree of generalizability.

Notwithstanding the strengths of the present study, there are several limitations that warrant caution when interpreting results. First, comparisons across scenario-based lab studies and retrospective field studies are complex and must be interpreted with caution, as these methods differ in how constructs are operationalized. Again, emphasis is placed on the fact that MSEM analyses used in the present study compared relationships across studies and did not formally equate manipulated and measured operationalizations of offender motives across studies. Thus, motives presented to participants in the lab study are recognizably different than perceived motives discerned by participants in the field study. Nevertheless, manipulation check results in the lab study suggested that participants' perceptions significantly reflected the motives that were presented, reducing concerns regarding the distinction between given and perceived motives in this study. However, because substantial and meaningful differences may exist between an offender's true motive and the motive perceived by others, results should be interpreted with due caution and are limited to those cases where victim perceptions reflect actual underlying offender motives.

While MSEM offers a more empirical approach to examining generalizability, interpretations of findings rest on the similarity of construct operationalizations across studies. For instance, it is arguable whether hypothetical anger is similar enough to retrospective anger to warrant a meaningful comparison. On one hand, both deal with the emotional construct of anger. On the other hand, the expectation of anger is qualitatively different that the recollection of anger. Nevertheless, it is important to note that 
this criticism is not unique to the MSEM approach, but may raise concerns anytime findings are compared across research methods. Thus, the MSEM approach advanced in this study is best viewed as an advancement in testing generalizability, not a completely objective or fail-proof test of equality between study findings.

Second, although considerable efforts were taken to ensure internal validity, readers may question the external validity of some study findings. While this study explicitly tested generalizability across method of study, issues of generalizability are complex, and multiple studies are needed to replicate findings across other conditions such as: industry and job type, populations (e.g., gender, age groups), type of offenses, and cultures and countries. While these issues of generalizability remain in question, this study does provide insights into generalizability across offense type, student and faculty populations, and research methods, and demonstrates how MSEM may be used to test other issues of generalizability.

Another limitation is that indirect effects may not have normal distributions and often have inflated standard errors (Preacher \& Hayes, 2004), potentially leading to overly conservative findings and an increased chance of Type II error. Accordingly, non-significant findings should be interpreted with caution, and future research is needed to further test indirect relations in field settings.

It is noteworthy that tests of generalizability provided insights into where findings differed across studies, not why differences existed. Thus, future research may explore the cause of these differences. For instance, stage of moral development has been found to differ with education level (Rest, Narvaez, Bebeau, \& Thoma, 1999), which differed across samples in the present study. Future research may also examine the effects of victim gender, as women may respond differently than men both emotionally and behaviorally when socially undermined. Future research and replication is also needed to further rule out concerns of common method variance between self-report measures of severity, emotion, and behavioral reactions that may have inflated relations in these variables. Although the use of experimental design and results from MCFA model comparisons are consistent with arguments by Spector (2006) suggesting that common method variance may be an overstated concern in organizational studies, additional experimental and longitudinal research is needed to replicate findings and further rule out concerns of $\mathrm{CMV}$, particularly between mediator variables and outcomes, as mediators were not experimentally manipulated in this study.

Future research may also explore the accuracy of victim perceptions and how perceptions of offender motives are determined by individual differences, social processes, and situational cues that may shape attributions of malice or greed. Research may also map out a broader constellation of motives from both offender and victim perspectives. For instance, an offense may result from a well-intentioned colleague who may have been innocently trying to help protect another from "unnecessary" details, and actually prevented the victim from receiving important information. Research may also examine individual differences and situational factors that may moderate responses and help determine when a person may reconcile rather than retaliate or avoid.

In summary, the present study provided empirical evidence that perceived offender malice and greed uniquely impact cognitive and emotional process variables, and ultimately predict behavioral reactions to social undermining. These findings are instrumental in understanding conflict escalation, avoidance and blocked communication, and grudges in the workplace. An improved understanding of this process can thus help organizations, researchers, and employees successfully address workplace mistreatment and promote more favorable work environments and experiences.

\section{Acknowledgments}

I would like to thank Karl Aqunio, Bruce Avolio, Becky Bennett, Theresa Glomb, Steve Jex, Marie Mitchell, Tom Tripp and Mary Uhl-Bien for helpful comments on earlier versions of this study.

\section{References}

Anderson and Gerbing, 1988 - J. C. Anderson and D. W. Gerbing, Structural equation modeling in practice: A review and recommended two-step approach, Psychological Bulletin 103 (1988), pp. 411-423.

Andersson and Pearson, 1999 - L. M. Andersson and C. M. Pearson, Tit for tat? The spiraling effect of incivility in the workplace, Academy of Management Review 24 (1999), pp. 452-471.

Aquino and Douglas, 2003 - K. Aquino and S. Douglas, Identity threat and antisocial behavior in organizations: The moderating effects of individual differences, aggressive modeling, and hierarchical status, Organizational Behavior and Human Decision Processes 90 (2003), pp. 195-208.

Aquino et al., 2004 - K. Aquino, S. Douglas, and M. J. Martinko, Overt anger in response to victimization: Attributional style and organizational norms as moderators, Journal of Occupational Health Psychology 9 (2004), pp. 152-164.

Aquino and Reed, 2002 - K. Aquino and A. Reed, The self-importance of moral identity, Journal of Personality and Social Psychology 83 (2002), pp. 1423-1440.

Aquino et al., 2001 - K. Aquino, T. M. Tripp, and R. J. Bies, How employees respond to personal offense: The effects of blame attribution, victim status, and offender status on revenge and reconciliation in the workplace, Journal of Applied Psychology 86 (2001), pp. 52-59.

Aquino et al., 2006 - K. Aquino, T. M. Tripp, and R. J. Bies, Getting even or moving on? Power, procedural justice, and types of offense as predictors of revenge, forgiveness, reconciliation and avoidance in organizations, Journal of Applied Psychology 91 (2006), pp. 653-668.

Berkowitz, 1990 - L. Berkowitz, On the formation and regulation of anger and aggression: A cognitive-neoassociationistic analysis, American Psychologist 45 (1990), pp. 494-503.

Bies and Tripp, 1996 - R. J. Bies and T. M. Tripp, Beyond trust: "Getting even" and the need for revenge. In: R.M. Kramer and T. Tyler, Editors, Trust in organizations, Sage, Newbury Park, CA (1996), pp. 246-260.

Bies and Tripp, 1998 - R. J. Bies and T. M. Tripp, Revenge in organizations: The good, the bad, and the ugly. In: R. W. Griffin, A. O'Leary-Kelly and J. M. Collins, Editors, Dysfunctional behavior in organizations: Non-violent dysfunctional behavior, JAI, Stamford, CT (1998), pp. 49-67.

Bing et al., 2007 - M. N. Bing, J. M. LeBreton, H. K. Davison, D. Z. Migetz, and L. R. James, Integrating implicit and explicit social cognitions for enhanced personality assessment, Organizational Research Methods 10 (2007), pp. 346-389.

Bradfield and Aquino, 1999 - M. Bradfield and K. Aquino, The effect of blame attributions and offender likableness on forgiveness and revenge in the workplace, Journal of Management 25 (1999), pp. 607-631.

Dictionary of Law, 2006 - Dictionary of Law (2006). http://dictionary.law.com

DPP v. Smith case, 1961 - DPP v. Smith, (1961). AC 290.

Duffy et al., 2002 - M. K. Duffy, D. C. Ganster, and M. Pagon, Social undermining in the workplace, Academy of Management Journal 45 (2002), pp. 331-351. 
Duffy et al., 2006a - M. K. Duffy, D. C. Ganster, J. D. Shaw, J. L. Johnson, and M. Pagon, The social context of undermining behavior at work, Organizational Behavior and Human Decision Processes 101 (2006), pp. 105-126.

Duffy et al., 2006b - M. K. Duffy, J. D. Shaw, K. L. Scott, and B. J. Tepper, The moderating roles of self-esteem and neuroticism in the relationship between group and individual undermining behavior, Journal of Applied Psychology 91 (2006), pp. 1066-1077.

Dunn and Schweitzer, in press - J. Dunn and M. Schweitzer, Invidious comparisons and insidious behaviors: Envy and social undermining at work. Paper presented at the annual meeting of the Academy of Management, Honolulu, HI (2005).

Folger and Cropanzano, 1998 - R. Folger and R. Cropanzano, Organizational justice and human resource management, Sage, Thousand Oaks, CA (1998).

Georgakopoulos, 2004 - A. Georgakopoulos, The role of silence and avoidance in interpersonal conflict, Peace and Conflict Studies $\mathbf{1 1}$ (2004), pp. 85-95.

Glomb, 2002 - T. M. Glomb, Workplace anger and aggression: Informing conceptual models with data from specific encounters, Journal of Occupational Health Psychology 7 (2002), pp. 20-36.

Heider, 1958 - F. Heider, The psychology of interpersonal relations, Wiley, Oxford, England (1958).

James et al., 2005 - L. R. James, M. D. McIntyre, C. A. Glisson, P. D. Green, T. W. Patton, and J. M. LeBreton et al., A conditional reasoning measure for aggression, Organizational Research Methods 8 (2005), pp. 69-99.

Kim et al., 2008 - T. Kim, D. C. Shapiro, K. Aquino, V. K. G. Lim, and R. J. Bennett, Workplace offense and victim reactions: The victim-offender (dis)similarity, offense type, and cultural differences, Journal of Organizational Behavior 29 (2008), pp. 415-433.

Kuppens et al., 2004 - P. Kuppens, I. Van Mechelen, and M. Meulders, Every cloud has a silver lining: Interpersonal and individual differences determinants of anger-related behaviors, Personality and Social Psychology Bulletin 30 (2004), pp. 1550-1564.

Lazarus, 1999 - R. S. Lazarus, Stress and emotion: A new synthesis, Springer Publishing Co, NY (1999).

Lewin, 1936 - K. Lewin, Principles of Topological Psychology, McGrawHill, NY (1936).

Locke, 1986 - E. A. Locke, Generalizing from laboratory to field settings, Lexington Books, Lexington, MA (1986).

Martinko and Zellars, 1998 - M. J. Martinko and K. L. Zellars, Toward a theory of workplace violence: A cognitive appraisal perspective. In: R. Griffin, A. O'Leary-Kelly and J. Collins, Editors, Dysfunctional behavior in organizations: Violent and deviant behavior, JAI Press, Stamford, CT (1996), pp. 1-42.

McCullough et al., 1998 - M. E. McCullough, K. C. Rachal, S. J. Sandage, E. L. Worthington Jr., S. W. Brown, and T. L. Hight, Interpersonal forgiving in close relationships: II Theoretical elaboration and measurement, Journal of Personality and Social Psychology 75 (1998), pp. 1586-1603.

McCullough et al., 1997 - M. E. McCullough, E. L. Worthington, and K. C. Rachal, Interpersonal forgiving in close relationships, Journal of Personality and Social Psychology 73 (1997), pp. 321-336.

Merriam-Webster, 2006 - Merriam-Webster (2006). www.m-w.com

Miller, 2001 - D. T. Miller, Disrespect and the experience of injustice, Annual Review of Psychology 52 (2001), pp. 527-553.

Moore, 1998 - M. Moore, Placing Blame: A general theory of criminal law, Clarendon Press, Oxford (1998).
O'Conner et al., 2001 - D. B. O'Conner, J. Archer, and F. W. Wu, Measuring aggression: Self-reports, partner reports, and responses to provoking scenarios, Aggressive Behavior 27 (2001), pp. 79-101.

Povinelli, 2001 - D. J. Povinelli, On the possibilities of detecting intentions prior to understanding them. In: B.F. Malle, L.J. Moses and D.A. Baldwin, Editors, Intentions and intentionality: Foundations of social cognition, MIT Press, Cambridge, MA (2001), pp. 225-248.

Preacher and Hayes, 2004 - K. J. Preacher and A. Hayes, SPSS and SAS procedures for estimating indirect effects in simple mediation models, Behavior Research Methods, Instruments, \& Computers 36 (2004), pp. 717-731.

Reeder et al., 2002 - G. D. Reeder, S. Kumar, M. Hesson-McInnis, and D. Trafimow, Inferences about the morality of an aggressor: The role of perceived motive, Journal of Personality $\mathcal{E}$ Social Psychology 83 (2002), pp. 789-803.

Rest et al., 1999 - J. Rest, D. Narvaez, M. J. Bebeau, and S. J. Thoma, Postconventional moral thinking: A neo-Kohlergian approach, Lawrence Erlbaum, Mahwah, NJ (1999).

Rudolph et al., 2004 - U. Rudolph, S. C. Roesch, T. Greitemeyer, and B. Weiner, A meta-analytic review of help giving and aggression from an attributional perspective: Contributions to a general theory of motivation, Cognition and Emotion 18 (2004), pp. 815-848.

Scott, 1985 - J. C. Scott, Weapons of the weak: Everyday forms of peasant resistance, Yale University Press, New Haven (1985).

Shapiro and Bies, 1994 - D. L. Shapiro and R. J. Bies, Threats, bluffs, and disclaimers in negotiations, Organizational Behavior and Human Decision Processes 60 (1994), pp. 14-35.

Spector, 2006 - P. E. Spector, Method variance in organizational research: Truth or urban legend?, Organizational Research Methods 9 (2006), pp. 221-232.

Taylor et al., 2000 - S. E. Taylor, L. Cousino-Klein, B. P. Lewis, T. L. Gruenewald, R. A. Gurung, and J. A. Updegraff, Biobehavioral responses to stress in females: Tend-and-befriend, not fight-or-flight, Psychological Review 107 (2000), pp. 411-429.

Trevino, 1992 - L. K. Trevino, The social effects of punishment in organizations: A justice perspective, Academy of Management Review 17 (1992), pp. 647-676.

Trevino and Ball, 1992 - L. K. Trevino and G. A. Ball, The social implications of punishing unethical behavior: Observers cognitive and affective reactions, Journal of Management 18 (1992), pp. 7514-7768.

TXO Production Corp. v. Alliance Resources Corp, 1993 - TXO Production Corp. v. Alliance Resources Corp. (1993). 509 US 443.

Vandenberg and Lance, 2000 - R. J. Vandenberg and C. E. Lance, A review and synthesis of the measurement invariance literature. Suggestions, practices, and recommendations for organizational research, Organizational Research Methods 3 (2000), pp. 4-70.

Vonk, 1998 - R. Vonk, The slime effect: Suspicion and dislike of likeable behavior toward superiors, Journal of Personality and Social Psychology 74 (1998), pp. 849-864.

Weiner, 1995 - B. Weiner, Judgments of responsibility, Guilford, New York (1995).

Weiner, 2006 - B. Weiner, Social motivation justice and the moral emotions, Lawrence Erlbaum Associates, Mahwah, NJ (2006).

Williams et al., 2003 - L. J. Williams, J. R. Edwards, and R. J. Vandenberg, Recent advances in causal modeling methods for organizational and management research, Journal of Management 29 (2003), pp. 903-936. 